\title{
Hydraulic and Structural Analysis of Complex Cross-Section Reinforced Concrete Pipes to Improve Sewage Flow in a Combined Sewer System
}

\author{
Hyon Wook Ji ${ }^{1}{ }^{\mathbb{D}}$, Jeong-Hee Kang ${ }^{1}$, Dan Daehyun Koo ${ }^{2} \mathbb{D}$ and Sung Soo Yoo ${ }^{1, *}$ \\ 1 Department of Environment Research, Korea Institute of Civil Engineering and Building Technology, 283, \\ Goyang-daero, Ilsanseo-gu, Goyang-si 10223, Korea; jihyonwook@kict.re.kr (H.W.J.); \\ kangjeonghee@kict.re.kr (J.-H.K.) \\ 2 Department of Engineering Technology, Indiana University-Purdue University Indianapolis (IUPUI), 799W. \\ Michigan St. ET 314J, Indianapolis, IN 46202, USA; dankoo@iupui.edu \\ * Correspondence: yoosungsoo@kict.re.kr; Tel.: +82-10-8863-1569
}

Citation: Ji, H.W.; Kang, J.-H.; Koo, D.D.; Yoo, S.S. Hydraulic and Structural Analysis of Complex Cross-Section Reinforced Concrete Pipes to Improve Sewage Flow in a Combined Sewer System. Water 2021, 13, 3304. https://doi.org/10.3390/ w13223304

Academic Editor: Enrico Creaco

Received: 26 October 2021

Accepted: 20 November 2021

Published: 22 November 2021

Publisher's Note: MDPI stays neutral with regard to jurisdictional claims in published maps and institutional affiliations.

Copyright: () 2021 by the authors. Licensee MDPI, Basel, Switzerland. This article is an open access article distributed under the terms and conditions of the Creative Commons Attribution (CC BY) license (https:// creativecommons.org/licenses/by/ $4.0 /)$.

\begin{abstract}
A complex cross-section reinforced concrete pipe that combines a sub-pipe for the flow of sewage in dry weather and a main pipe for the flow of rainwater was developed to reduce sedimentation of the combined sewer system in dry weather. The sub-pipe was designed, considering the flow velocity, constructability, and maintenance. By fitting the sewage data in the dry weather to the normal distribution, the ratio of the cross-sectional area of sewage flow to that of the pipe was determined to be approximately 0.418 , which could cover $99.85 \%$ of the sewage volume of the target site. Based on this ratio, the diameter of the sub-pipe corresponding to the combined sewer system with a pipe diameter between 450 and $1300 \mathrm{~mm}$ was determined. The hydraulic performance analysis results showed that the flow velocity increased by 11 to $12 \%$ compared to the circular pipe based on the full sub-pipe and by more than $15 \%$ depending on the water level. The shear stress increased by more than $16.5 \%$, and higher tractive force was observed. Structural safety was determined as the crack load and failure load far exceeded the minimum criteria, thereby verifying the feasibility and field applicability of the complex cross-section reinforced concrete pipe.
\end{abstract}

Keywords: combined sewer system; complex cross-section; sedimentation; reinforced concrete pipe; numerical modeling

\section{Introduction}

Sewer systems play an important role in public health, and sedimentation in sewer pipes is a chronic problem that degrades the quality of public services. Rainfall, cracks, and damage in sewer pipes, and poor connection of sewer pipes introduce sand and external pollutants into pipes. The low flow velocity of sewage causes sedimentation of external substances and pollutants involved with sewage [1-3], and intensifies the coagulation of fat, oil, and grease [4]. Particularly, in junction and bend manholes, sedimentation restricts the recirculation zones, which can lead to the manhole getting submerged $[5,6]$. Sedimentation also aggravates the odor in sewers by stagnating odor-causing substances or causing anaerobicization [3,7]. Anaerobicization creates an environment that is conducive to the production of hydrogen sulfide for microorganisms, triggering corrosion in the concrete sewer pipe [8]. For combined sewer systems that drain both sewage and rainwater, odor is discharged to the outside through manholes and street inlets, and rainwater washes sediments, thereby deteriorating the combined sewer overflow (CSO) concentration $[9,10]$.

In South Korea, the average annual precipitation is $1277 \mathrm{~mm}, 50-60 \%$ of which occurs in summer; the sewage volume is less than $1 \%$ of the rainwater volume in most areas. The flow velocity of the combined sewer system must be within the range of $0.8-3 \mathrm{~m} / \mathrm{s}$ under the design volume of rainfall in accordance with the Korea Construction Standards [11]. Under 
dry weather, sewage flow becomes relatively smaller, and the flow velocity drops below the minimum value. This causes problems of sedimentation, odor, and CSO deterioration, which become severe in areas with low precipitation concentration.

Until the late 1800s, sewers were constructed in various shapes using bricks [12]. Sewer design with a small lower part for sewage flow and a large upper part for drainage of a large amount of rainwater during rainfall with convenient access for maintenance personnel was dominant. The principle that the hydraulic radius of the high-water level in the small pipe is larger than that of the low water level in the large pipe under the same discharge increases the flow velocity. This design was used to address the problem of the occurrence of sedimentation and odor caused by the low discharge and low flow velocity in dry weather conditions. Subsequently, the economic efficiency of concrete sewer pipes was evaluated, allowing sewer pipes with simple circular or square shapes that are easy to produce in factories to be commonly used. Sewer pipes with simple shapes are used because of the temporal and economic efficiency of construction; however, they cause sedimentation and odor problems due to the difference in discharge between dry and wet weather condition in the combined sewer system.

To address this problem, research has been conducted on the introduction of sewer pipes with a complex cross-section using modern materials rather than bricks. A new challenge is that the structural strength, sewer design, construction, and mass production must be considered in addition to the cross-sectional shape. Although the sewer design standards of Korea allow the use of a complex cross-section, there are few cases where it has been applied due to the difficulty in mass production. Elliptical pipes [13] or egg-shaped sewer pipes [14] are close to the circular shape and have no edges, making mass production relatively easy. Therefore, efforts to commercialize them by conducting research on the proportion of the internal space or standardization have been made.

The complex cross-section reinforced concrete pipe proposed in this study has a shape close to the complex cross-section used in the past. The two overlapped circular cross sections make flow of sewage different from that of rainwater in the combined sewer system and increase the velocity of sewage. In this study, a design to improve the applicability of this pipe and the process of testing its hydraulic and structural performance were introduced to solve the aforementioned challenges.

\section{Materials and Methods}

In this chapter, theories and various methods to design the geometry of complex cross-section reinforced concrete pipe and evaluate its performance are introduced. The fundamental theory of sewage flow explains the sedimentation and flow velocity of the sewer system and is a criterion for evaluating the flow performance of the pipe. The design method determines the specifications of the pipe. The velocity equation, computational fluid dynamic (CFD) modeling, and pilot tests were used for evaluation of the flow performance, and the breaking test and finite element analysis (FEA) were conducted for that of the structural performance.

\subsection{Fundamental Theory of Sewage Flow}

Tractive force is the force of water, which moves the particles lying on the bottom of a sewer pipe. According to Bizier [8], tractive force is generated if the shear stress of water (Equation (2)) is larger than the critical shear stress (Equation (1)) of sand particles in gravity sewers.

$$
\begin{gathered}
\tau_{c}=0.867 d^{0.277} \\
\tau=\gamma R_{h} S
\end{gathered}
$$

where $\tau_{c}$ is the critical shear stress of sand particles $\left(\mathrm{N} / \mathrm{m}^{2}\right), d$ is the diameter $(\mathrm{mm})$ of the particle with a specific gravity of $2.7, \tau$ is the average shear stress of water $\left(\mathrm{N} / \mathrm{m}^{2}\right)$, $\gamma$ is the specific weight of water $\left(9800 \mathrm{~N} / \mathrm{m}^{3}\right), R_{h}$ is the hydraulic radius $(\mathrm{m})$, and $S$ is the slope of the sewer pipe $(\mathrm{m} / \mathrm{m})$. The shear stress of water can be increased by 
increasing the hydraulic radius or the slope of the sewer pipe. We aim to increase the shear stress by increasing only the hydraulic radius using complex cross-section sewer pipes without increasing the slope. An increase in hydraulic radius increases the flow velocity of sewage. In general, the flow velocity of a sewer pipe is determined by Manning's equation (Equation (3)) [15]. According to Equation (3), the flow velocity is a function of the roughness coefficient $(n)$, hydraulic radius $\left(R_{h}\right)$, and slope $(S)$. Among them, the hydraulic radius is increased by a complex cross-section. Thus, the flow velocity can be increased without increasing the roughness coefficient and slope.

$$
v=\frac{1}{n} R_{h}^{2 / 3} S^{1 / 2}
$$

where $v$ is the flow velocity $(\mathrm{m} / \mathrm{s})$, and $n$ is Manning's roughness coefficient $\left(\mathrm{s} / \mathrm{m}^{1 / 3}\right)$. Based on the above theories, a complex cross-section sewer pipe was designed, and its performance was evaluated.

\subsection{Design Method of a Complex Cross-Section}

The complex cross-section sewer pipe in the combined sewer system has a shape that combines a sanitary sewer and a rainwater sewer. Here, the rainwater sewer has a large size and is the main pipe, while the sanitary sewer with a small size is the sub-pipe (Figure 1). The main pipe becomes larger in areas with high quantity and concentration of precipitation, whereas the sub-pipe becomes larger as the population density increases and toward the downstream area.

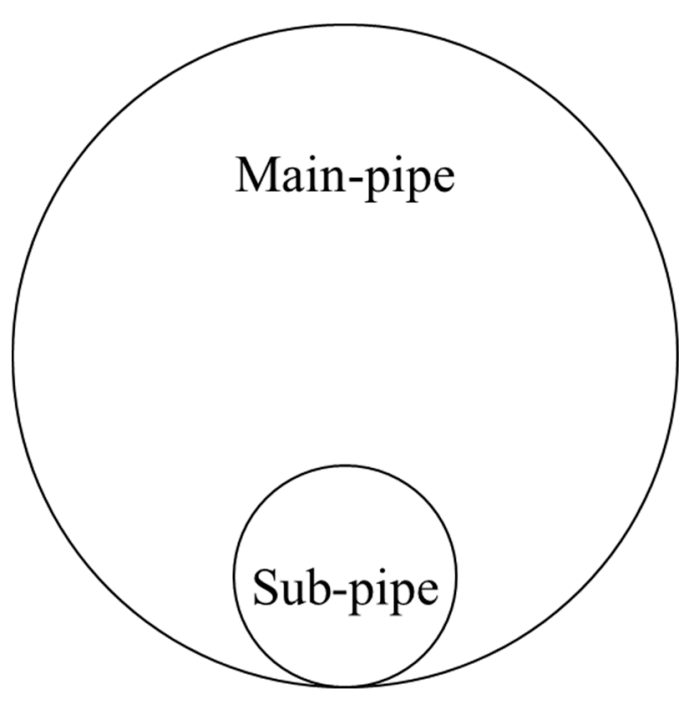

Figure 1. Classification of the sub-pipe for sewage and main pipe for rainwater.

As the main pipe is already standardized, it is reasonable to use the standard specifications. The sub-pipe, however, must be able to realize efficient flow velocity while sufficiently accommodating the sewage volume discharged from the combined sewer system. Figure 2 shows the logical flow of determining the size of the sub-pipe for achieving this purpose. 


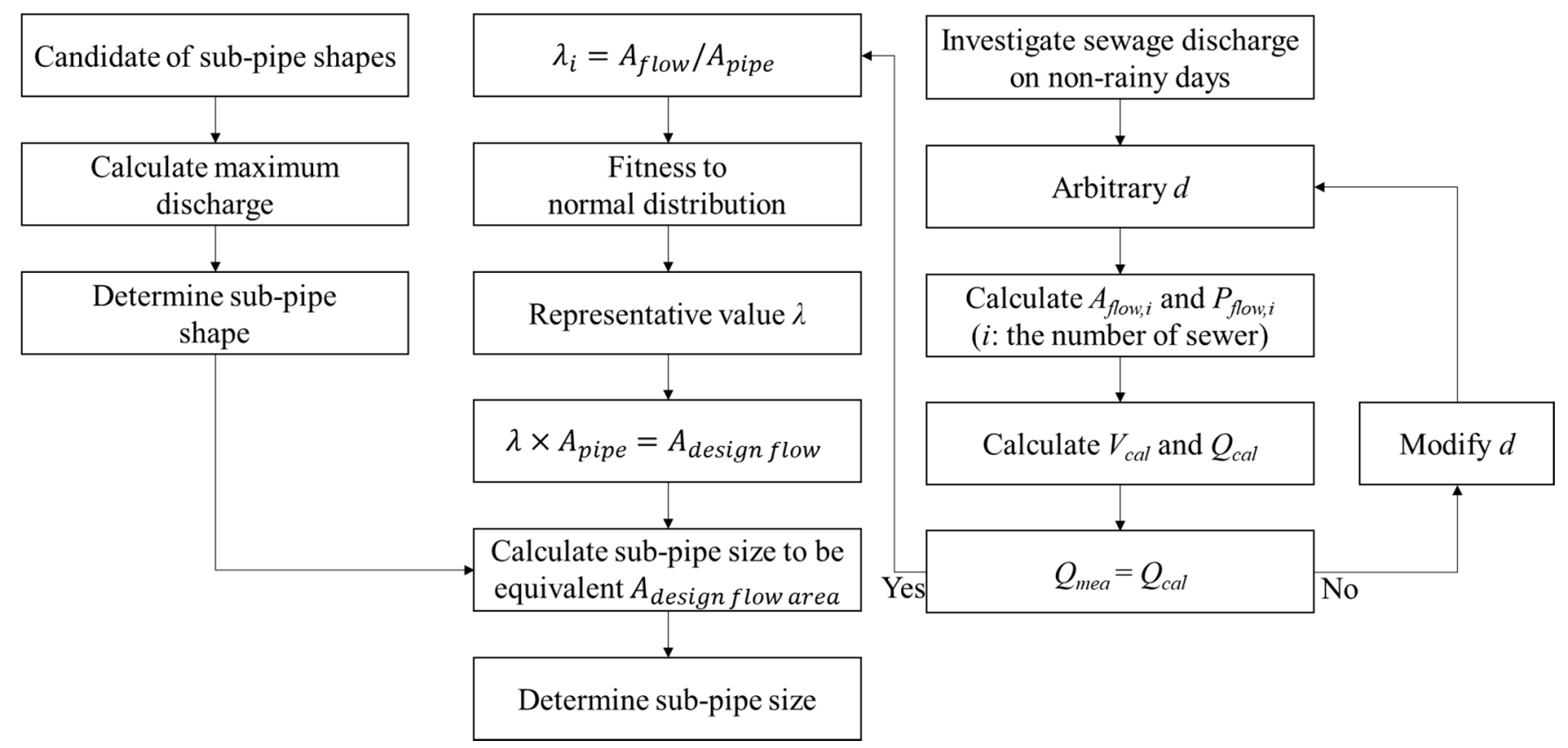

Figure 2. Flow chart to determine sub-pipe size.

To determine the size of the sub-pipe suitable for the sewage volume, the sewage volume of the combined sewer system must be investigated first. Once this is done, the water depth and cross-sectional area of flow can be calculated inversely using the trialand-error method through Manning's equation (Equation (3)). The velocity $\left(V_{\text {cal }}\right)$ and discharge $\left(Q_{c a l}\right)$ calculated using arbitrary depth $(d)$ are compared with discharge $\left(Q_{\text {mea }}\right)$ from measurement or investigation, and $d$ is modified until $Q_{c a l}$ is same as $Q_{\text {mea }}$. In addition, $\lambda_{i}$ (Equation (4)), which is the ratio of the cross-sectional area of flow to the cross-sectional area of pipe, can be calculated.

$$
\lambda_{i}=\frac{A_{\text {flow, } i}}{A_{\text {pipe }, i}}
$$

$A_{\text {flow }, i}$ is the cross-sectional area $\left(\mathrm{m}^{2}\right)$ of flow for the sewage volume at $i$-th sewer pipe, $A_{\text {pipe, }}$ is the cross-sectional area $\left(\mathrm{m}^{2}\right)$ of the sewer pipe at $i$-th sewer pipe, $\lambda_{i}$ is the ratio of the cross-sectional area of flow to the cross-sectional area of pipe at $i$-th sewer pipe. A statistical method was used because obtaining data from all sewer pipes across the country is not possible. It is statistically reasonable to estimate the parametric distribution by fitting $\lambda_{i}$ to Equation (5) [16] of the normal distribution. There are various distribution functions, including Gumbel and lognormal, but the normal distribution is the most common and has no restriction on application. It has a horizontally symmetrical bell shape in which probabilities according to $\lambda_{i}$ are continuously matched.

$$
f(x)=\frac{1}{\sqrt{2 \pi} \sigma} e^{-(x-m)^{2} / 2 \sigma^{2}}
$$

$f(x)$ is a continuous probability density function for variable $x . \sigma$ is the standard deviation, and $\mathrm{m}$ is the mean. In the normal distribution, the representative value $\lambda$ of $\lambda_{i}$ with a certain probability is determined. $\lambda$ multiplied by a cross-sectional area of each sewer pipe is equivalent to the design flow area $\left(A_{\text {design flow }}\right)$. In dry weather conditions, flow area of sewage is designed to $A_{\text {design flow }}$.

In contrast, the shape of the sub-pipe can be determined. The sub-pipe that has high flow velocity and large discharge under the same area is efficient. The flow velocity and discharge are calculated using Manning's equation to determine the most efficient shape. Because angled edges are unfavorable for maintenance as there is a possibility that dredging will not be clean, curves are favorable. Once the shape of the sub-pipe has been 
determined, its size is inversely calculated from $A_{\text {design flow }}$. When the size and shape of each pipe are determined, the maximum discharge is finally examined by obtaining the full pipe flow velocity.

\subsection{Flow Performance Modeling}

ANSYS CFX 19.1 was used for numerical modeling for solving the 3D Reynoldsaveraged Navier-Stokes equations [17]. Among the multiphase techniques, volume of fraction (VOF) was applied for modeling both water and air inside the pipe, and the status of the fluid was analyzed using a homogeneous model. The K- $\varepsilon$ turbulence model and hydrostatic pressure buoyancy model were applied. The bulk mass flow rate was given as the inlet condition and the opening pressure as the outlet condition, and a steady state was assumed for analysis. To consider different cases, three slopes of $0.005,0.01$, and 0.015 , and two Manning roughness coefficients of $0.01 \mathrm{~s} / \mathrm{m}^{1 / 3}$ (polyvinyl chloride; PVC) and $0.013 \mathrm{~s} / \mathrm{m}^{1 / 3}$ (concrete) are introduced. The pipe was designed with an unstructured (block-structured) non-uniform mesh of $1.44 \times 10^{6}$ elements, $1.47 \times 10^{6}$ nodes, and $20 \mathrm{~m}$ length. Height of elements ranged between $1 \mathrm{~mm}$ near the wall and $5 \mathrm{~mm}$ at the center of the pipe.

\subsection{Tractive Force Pilot Test}

The tractive force theory that represents the movement of sand particles in a water channel (Equations (1) and (2)) is a theory on sand particles with a specific gravity of 2.7, and some errors may occur in actual sand that has various densities for each particle. To supplement this, a pilot test in the same size as the actual sewer pipe was performed as shown in Figure 3. An experiment was performed under the same conditions of the roughness coefficient, slope, and discharge to examine the tractive force improvement effect by the complex cross-section.

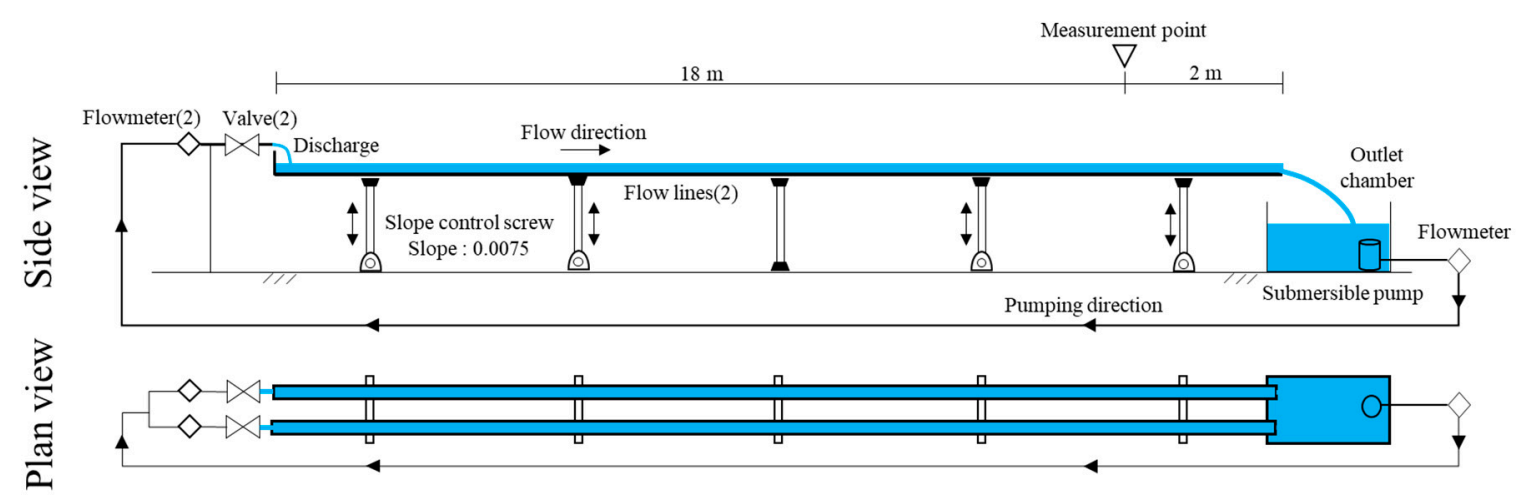

Figure 3. Configuration of sewer pipelines for tractive force test.

Two water channels of $20 \mathrm{~m}$ length were arranged in parallel, and the slope was adjusted to $0.0075 \mathrm{~m} / \mathrm{m}$ by the slope control motors located in front of and behind the water channels. The two water channels represent the main pipe and sub-pipe. The main pipe was prepared by cutting a $450 \mathrm{~mm}$ diameter PVC pipe in half, and the sub-pipe by cutting a $150 \mathrm{~mm}$ diameter PVC pipe in half. These two pipes with a $20 \mathrm{~m}$ length were placed on each water channel. The Manning's coefficient of PVC is $0.01 \mathrm{~s} / \mathrm{m}^{1 / 3}$. Water was collected in the outlet chamber and then sent to the upstream area of the water channels using a pump. The water was divided into two parts, and then one fell into the main pipe and the other into the sub-pipe. Three flowmeters were installed with one in the front of the pump and the remaining two in front of the valve of each water channel to measure the total discharge from the pump. The discharge was measured once more before the water fell into each water channel to verify the total discharge. In addition, the flow velocity and water level were measured at the measurement point located $18 \mathrm{~m}$ from the top of water channels. The flow velocity was measured using a contact-type propeller current 
meter and the water level using a ruler. The measured water level was converted into the flow velocity and discharge using Manning's equation, and each result was compared with measurements obtained by the flowmeters and averaged to minimize the error that may exist in the flowmeters and the current meter. The slope of the water channels was measured using an infrared distance and slope gauge.

In this test, tractive forces were indirectly measured from size of the particles moving on the channel and $f$ their critical shear stress. As shown in Equation (1), the critical shear stress of sand particles is exponentially proportional to the particle size. This means that the corresponding water channel has a larger tractive force as the particles transported have a larger size. To compare the tractive force in a circular pipe with that in the complex cross-section using the size of particles that can be transported, the sand with a particle size distribution containing particles with a maximum diameter of $5 \mathrm{~mm}$ was added to the top of the water channels as shown in Figure 4. The sand flowing out of the water channels was collected by receiving the water falling into the outlet chamber with a no. 50 sieve for $20 \mathrm{~min}$. After the test, the size of the sand collected from each water channel was compared to analyze the magnitude of tractive forces.

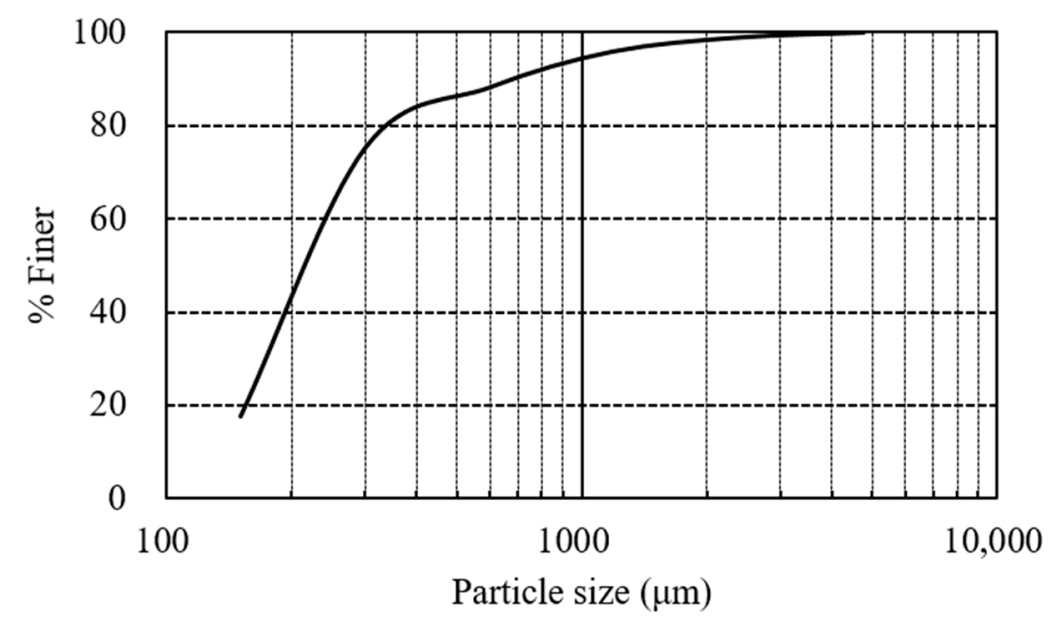

Figure 4. Particle size distribution curve.

\subsection{Structural Strength Test}

In this study, a sample that corresponds to the frequently used D600 mm was manufactured to make the complex cross-section reinforced concrete pipe, and an attempt was made to perform the corresponding quality test. There are, however, no regulations on the complex cross-section reinforced concrete pipe developed in this study. As an alternative, a quality test was conducted in accordance with the existing test method and standards for vibrated and rolled reinforced concrete (VR) pipes. In South Korea, the quality of VR pipes was evaluated by the three-edge bearing test (breaking test) specified in KS F 4402 [18]. In the case of D600 mm, a crack load of $34.5 \mathrm{kN} / \mathrm{m}$ and a failure load of $52 \mathrm{kN} / \mathrm{m}$ must be satisfied. The test was conducted in the presence of personnel from an authorized testing agency. Size measurements were performed, and the cracking and failure loads were checked.

\subsection{Structural Analysis Modeling}

Structural analysis was performed to theoretically evaluate the structural stability of the developed complex cross-section reinforced concrete pipe. Although the actual product is reinforced concrete pipe, modeling was performed using the unreinforced concrete pipe, excluding steel reinforcement. Accordingly, only the structural stability of the concrete structure was discussed. The ABAQUS 2020 version, which is the model used, analyzes changes in the internal and external states of an object under internal and external forces, such as stress and displacement, using the finite element method. Load conditions as in the 
three-edge bearing test of an actual sewer pipe were simulated by assigning the self-weight and line load. The line load was applied only to the body, except for the socket, to simulate the same state as in the lab experiment. The concrete damaged plasticity model was used as a concrete material model. The information proposed by Hafezolghorani et al. [19] was used for the physical properties of concrete, and some properties were used through linear interpolation based on the concrete compressive strength. We used $45 \mathrm{MPa}$, the design strength at 28 days of age used by sewer pipe manufacturers, as the concrete compressive strength. Accordingly, a dilation angle of $31^{\circ}$, an eccentricity of 0.1 , a stress ratio $(f b 0 / f c 0)$ of 1.16 , a $K c$ value of 0.67 , a viscosity of 0 , and a concrete elasticity of $31.7 \mathrm{GPa}$ were applied. We applied an eight-node three-dimensional solid (C3D8R) with reduced integration for analytical modeling, and the sewer pipe model was designed with a horizontally symmetrical structured mesh with $0.125 \times 10^{6}$ elements and $2.5 \mathrm{~m}$ in length.

\section{Results}

\subsection{Design of a Complex Cross-Section}

The size of the sub-pipe in which sewage flows is a main factor that determines the transportation and material efficiency of the pipe. It was assumed that $9.899 \mathrm{~L} / \mathrm{s}$ of sewage flowed in a pipe with a diameter of $450 \mathrm{~mm}$, a slope of 0.1 , and a Manning's roughness coefficient of $0.1 \mathrm{~s} / \mathrm{m}^{1 / 3}$. In this instance, the flow velocity was $1.004 \mathrm{~m} / \mathrm{s}$ based on Manning's equation. To increase this flow velocity of sewage, a semicircular sub-pipe was fabricated inside the sewer pipe, as shown in Figure 5. If the size of the sub-pipe is relatively small under the same discharge and slope, the water level rises above the sub-pipe, which dramatically increases the friction area and decreases the flow velocity. A small pipe diameter is also unfavorable for maintenance.

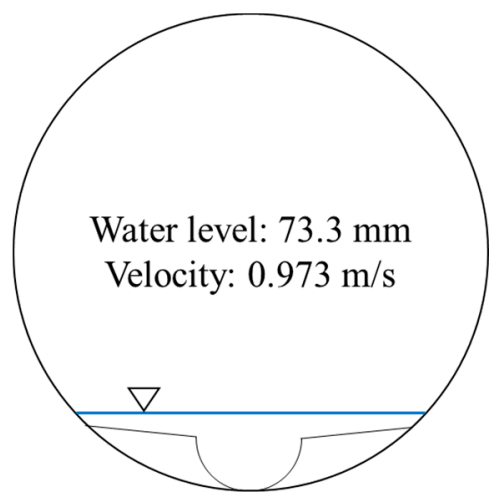

(a)

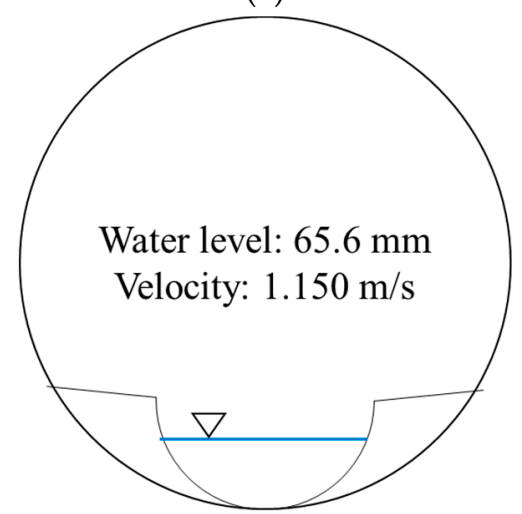

(c)

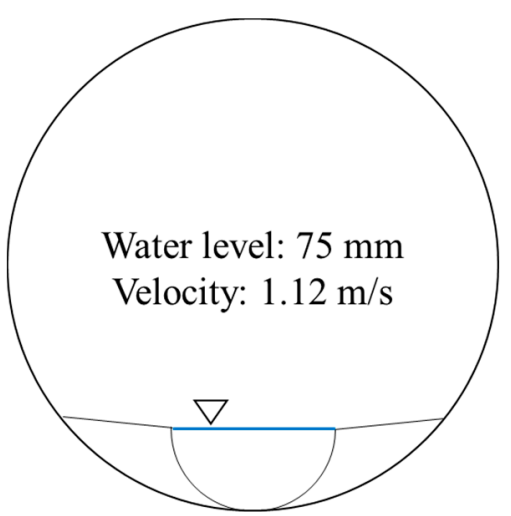

(b)

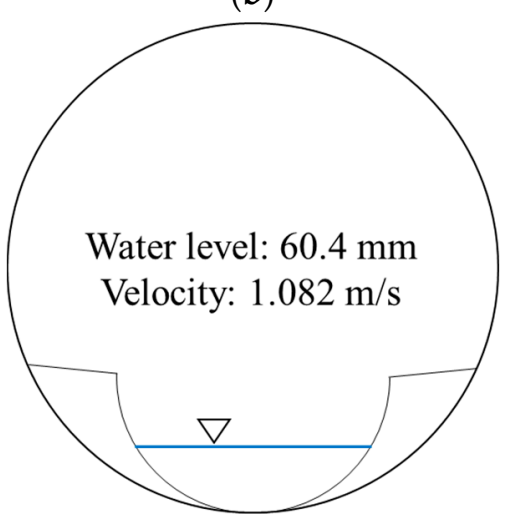

(d)

Figure 5. Changes in flow with the sub-pipe of 100 (a), 150 (b), 200 (c), and $250 \mathrm{~mm}$ (d) diameter in in a $450 \mathrm{~mm}$ diameter main pipe $\left(Q=9.899 \mathrm{~L} / \mathrm{s}, n=0.01 \mathrm{~s} / \mathrm{m}^{1 / 3}, S=0.01\right)$. 
In contrast, if the sub-pipe size is too large, the efficiency decreases because the hydraulic radius increase rate of the sub-pipe is low compared to the hydraulic radius of the main pipe. The ideal case is the one in which the sub-pipe is filled with sewage flow. It is important to determine the sub-pipe size that is not too large while preventing the discharge of sewage from overflowing.

To find the suitable sub-pipe size for discharge, the sewage volume data of 85,255 circular pipes with diameters between 450 and $1300 \mathrm{~mm}$, excluding adverse tilts and no discharge, in 24 sub-watersheds in Seoul, Korea, were used. The values of $\lambda_{i}$ obtained through the data exhibited a mean value of 0.0085 , a standard deviation of 0.0112 , and a median value of 0.0055 . The finding that the median value is smaller than the mean value indicates that the data are generally concentrated toward low values.

Table 1 shows the distribution of $\lambda_{i}$ in quartiles by sewer pipe size. Q3 indicates that $75 \%$ of the data are generally close to 0.01 , and Q2 indicates that $50 \%$ (median) is generally in the $0.004-0.01$ range. Q1 indicates that $25 \%$ is near 0.003 . The average for each size was not significantly different from the overall average of 0.0085 .

Table 1. Quartile of $\lambda_{i}$ in accordance with sewer pipe diameter.

\begin{tabular}{|c|c|c|c|c|c|c|c|c|c|c|}
\hline$D_{\text {pipe }}$ & 450 & 500 & 600 & 700 & 800 & 900 & 1000 & 1100 & 1200 & 1300 \\
\hline Q3 & 0.00829 & 0.00953 & 0.0117 & 0.0157 & 0.0148 & 0.0166 & 0.0135 & 0.0189 & 0.0146 & 0.00982 \\
\hline Q2 & 0.00464 & 0.00479 & 0.00638 & 0.00882 & 0.00831 & 0.00910 & 0.00766 & 0.0119 & 0.00730 & 0.00650 \\
\hline $\mathrm{Q} 1$ & 0.00259 & 0.00234 & 0.00317 & 0.00442 & 0.00366 & 0.00450 & 0.00307 & 0.00650 & 0.00274 & 0.00337 \\
\hline
\end{tabular}

A considerably large amount of sewer pipe data from Seoul was used, but this does not represent the whole data. The data were fitted to the normal distribution for parameter estimation. The highest probability is found at the mean, and the probability is close to zero at both extremes. Figure 6 shows the probability density curve of $\lambda_{i}$ created using the mean and standard deviation of $\lambda_{i}$. Owing to the characteristics of the normal distribution, $99.7 \%$ of $\lambda_{i}$ is included in the $m \pm 3 \sigma$ range. The tail sections out of the range represent $0.3 \%$. To include as much data as possible, the representative value $\lambda$ was set to $m+3 \sigma$, and its value was 0.0418 . This value contains $99.85 \%$ of the total data, including $0.15 \%$ represented by the left tail section.

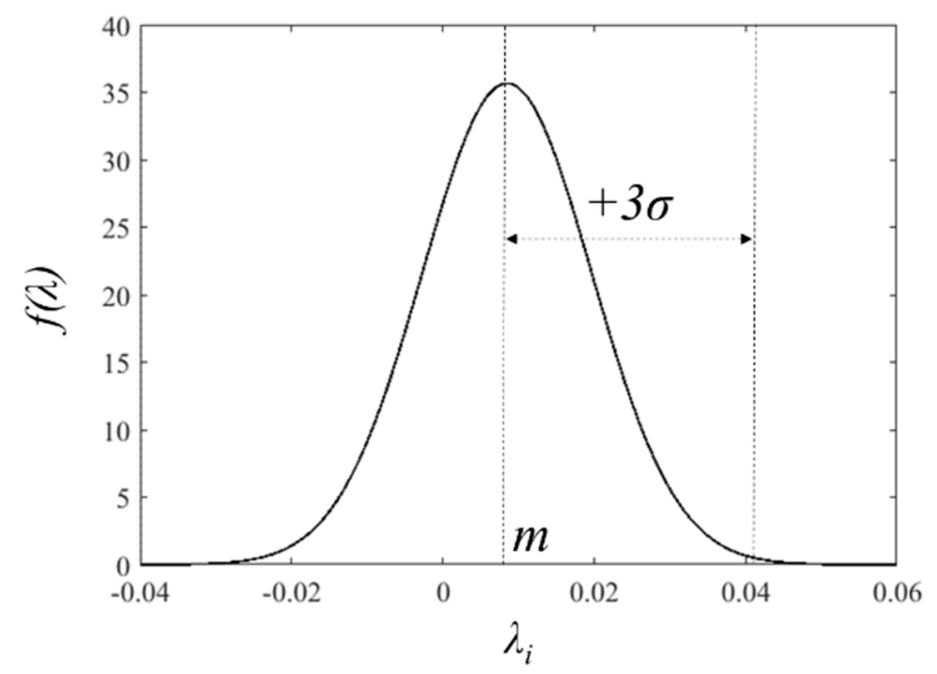

Figure 6. Normal distribution of $\lambda_{i}$. 
Various geometries can be considered for the sub-pipe. Because the presence of internal angles or a narrow width makes dredging or form removal difficult, curved shapes were considered. Among them, the cup and semicircle shapes were compared. Under the same conditions of cross-sectional area, Manning's coefficient, and slope, the maximum discharge of these sub-pipe shapes is shown in Figure 7. Discharge of sub-pipe of semicircle shape is always larger than that of sub-pipe of cup shape. The semicircle shape is favorable in terms of the flow velocity and discharge. The sub-pipe, which is a part that protrudes from the main pipe, is a structural weak point concentrating stress. If the protruding part is long and thin, structural safety is low. The cup shape may increase the flow velocity and discharge because the hydraulic radius varies depending on the length of the upper part, but the semicircle shape with a large width and a low height is appropriate when structural safety is also considered.

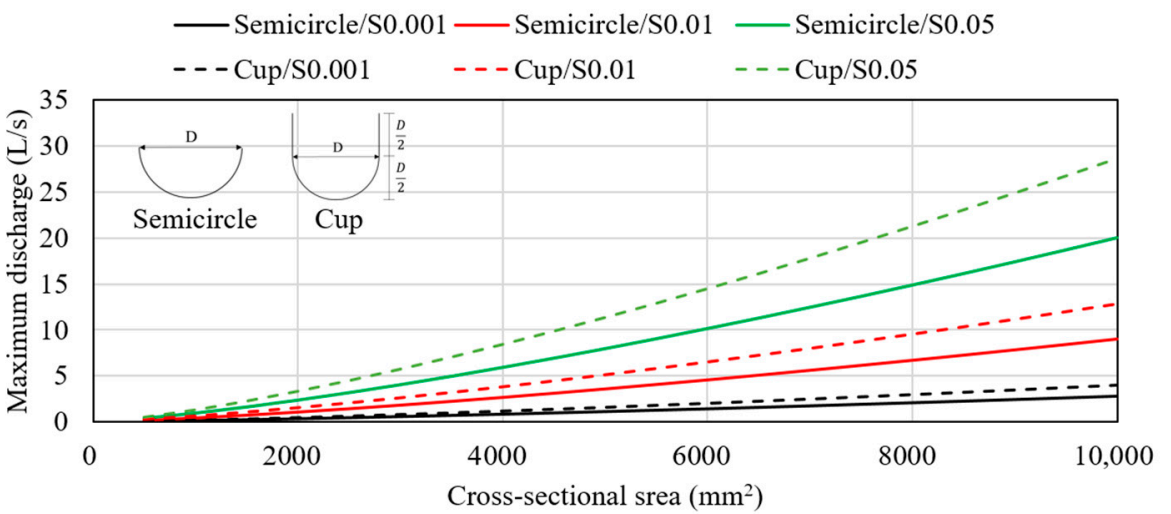

Figure 7. Flow capacity of two sub-pipes under the same conditions $\left(n=0.013 \mathrm{~s} / \mathrm{m}^{1 / 3}\right)$.

The cross-sectional area of the sub-pipe was obtained by multiplying the crosssectional area of the existing circular pipe by $\lambda$, and the diameter of the semicircle was inversely calculated from the area. The theoretical size of the sub-pipe with the crosssectional area corresponding to $\lambda=0.0418$, which was determined above, is $D_{\lambda}$ in Table 2 . It is practically difficult, however, to apply this value to the sub-pipe size. An important component of the sewer pipe is the manhole, and there is an invert to prevent sedimentation of the manhole. The size of the invert is equivalent to the downstream sewer pipe diameter. When the invert inside a manhole is fabricated, a PVC pipe in the corresponding size is used as a cast. PVC pipes are standardized and available in sizes of 100, 150, 200, and $250 \mathrm{~mm}$. Considering construction of the manhole invert, it is reasonable to match standards with the existing PVC pipes. In addition, $D_{\text {sub-pipe }}$ was designed to be larger than $D_{\lambda}$ so that the water level of sewage could not flow over the sub-pipe in dry weather conditions.

Table 2. Sub-pipe diameter according to main pipe diameter.

\begin{tabular}{ccccc}
\hline$D_{\text {main-pipe }}(\mathbf{m m})$ & $\lambda^{*} A_{\text {pipe }}\left(\mathbf{m m}^{\mathbf{2}}\right)$ & $\boldsymbol{D}_{\lambda}(\mathbf{m m})$ & $D_{\text {sub-pipe }}(\mathbf{m m})$ & Notation \\
\hline 300 & 2954 & 87 & 100 & D300/D100 \\
400 & 5253 & 116 & 150 & D400/D150 \\
450 & 6648 & 130 & 150 & D450/D150 \\
500 & 8207 & 145 & 150 & D500/D150 \\
600 & 11,819 & 173 & 200 & D600/D200 \\
700 & 16,087 & 202 & 200 & D700/D200 \\
800 & 21,011 & 231 & 250 & D800/D250 \\
900 & 26,592 & 260 & 300 & D900/D300 \\
1000 & 32,830 & 289 & 300 & D1000/D300 \\
1100 & 39,724 & 318 & 350 & D1100/D350 \\
1200 & 47,275 & 347 & 350 & D1200/D350 \\
1300 & 55,482 & 376 & 400 & D1300/D400 \\
\hline
\end{tabular}


The cross-section of the complex cross-section sewer pipe was designed as shown in Figure 8. The sub-pipe with a perfect semicircle shape is attached to the bottom of the main pipe. The distance between the centers of the two circles is $h=$ $\sqrt{\left(D_{\text {main-pipe }} / 2\right)^{2}-\left(D_{\text {sub-pipe }} / 2\right)^{2}}$, and the angle formed by the center of the main pipe and the diameter of the sub-pipe is $\theta=2 \cos ^{-1}\left(1-2 y / D_{\text {main-pipe }}\right) . y$ is the difference between the radius of the main pipe and $h$.

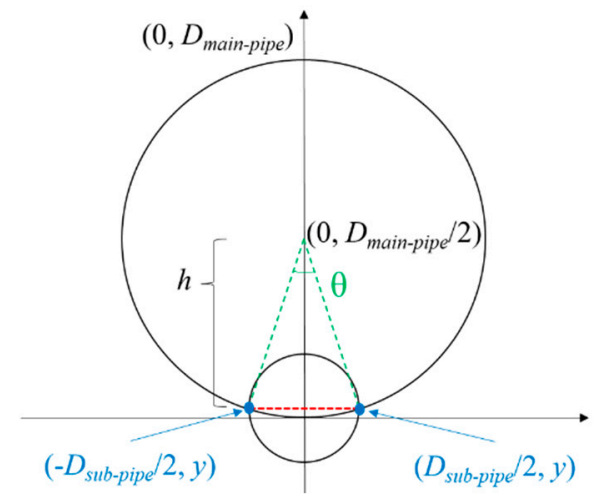

Figure 8. Geometry between the main pipe and sub-pipe.

\subsection{Flow Performance in Wet Weather Conditions}

Figure 9 compares the flow performance as one of CFD modeling cases. The diameters of the main- and sub-pipes are 450 and $150 \mathrm{~mm}$, respectively. A slope of 0.01 , a discharge of $0.007615 \mathrm{~m}^{3} / \mathrm{s}$, and Manning's roughness coefficient $0.013 \mathrm{~s} / \mathrm{m}^{1 / 3}$ were used. Because the level of sewage does not exceed half of the diameter of the sub-pipe, the analysis of the sub-pipe is identical to the analysis of the circular pipe with the same diameter and half the level. According to the modeling results, the water level $(75 \mathrm{~mm})$ and maximum flow velocity $(1.28 \mathrm{~m} / \mathrm{s})$ in the sub-pipe were higher than the water level $(51 \mathrm{~mm})$ and maximum flow velocity $(1.22 \mathrm{~m} / \mathrm{s})$ of the main pipe under the same discharge condition. This result is arranged as case 5 in Table 3 . Because the width of the water surface is long for the main pipe, the area in contact with air is large, and the area that decreases the flow velocity due to the shear force with air is larger. The area in contact with the bottom of the pipe is also large and, thus, the area that reduces the flow velocity is large. The principle of the hydraulic radius applies well, and the modeling results are the same as the design intent.

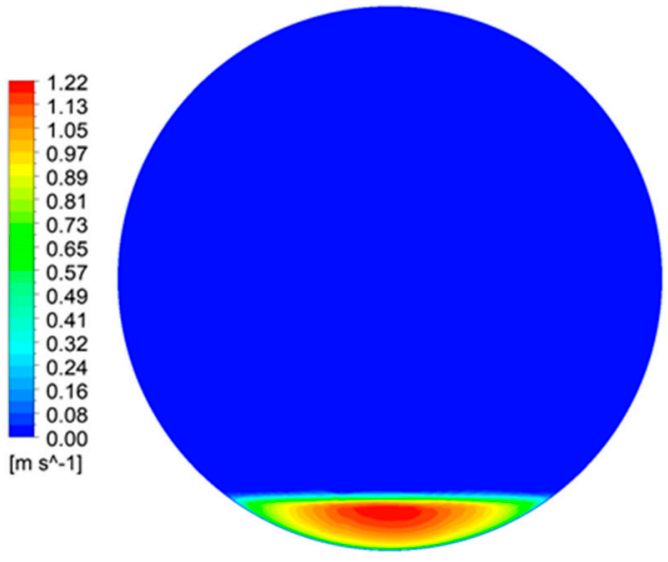

(a)

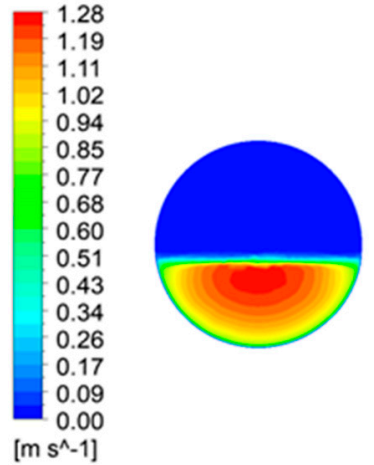

(b)

Figure 9. Velocity distribution in main pipe (a) and sub-pipe (b) by computation fluid dynamic modeling. 
Table 3. CFD results of circular pipe and complex cross-section pipe ( $D_{\text {main-pipe }}: 450 \mathrm{~mm}$, $\left.D_{\text {sub-pipe }}: 150 \mathrm{~mm}\right)$.

\begin{tabular}{|c|c|c|c|c|c|c|c|}
\hline Case No. & Slope & $\begin{array}{c}\text { Manning's } \\
\text { Roughness } \\
\text { Coefficient } \\
\left(\mathrm{s} / \mathrm{m}^{1 / 3}\right)\end{array}$ & $\begin{array}{c}\text { Discharge } \\
\left(\mathrm{m}^{3} / \mathrm{s}\right)\end{array}$ & Pipe & $\begin{array}{c}\text { Average } \\
\text { Velocity } \\
(\mathrm{m} / \mathrm{s})\end{array}$ & $\begin{array}{l}\text { Water Level } \\
(\mathrm{mm})\end{array}$ & $\begin{array}{c}\text { Average } \\
\text { Shear Stress } \\
\left(\mathrm{N} / \mathrm{m}^{2}\right)\end{array}$ \\
\hline \multirow{2}{*}{1} & \multirow{2}{*}{0.005} & \multirow{2}{*}{0.01} & \multirow{2}{*}{0.007} & Main pipe & 0.806 & 51 & 1.58 \\
\hline & & & & Sub-pipe & 0.868 & 75 & 1.84 \\
\hline \multirow{2}{*}{2} & \multirow{2}{*}{0.01} & \multirow{2}{*}{0.01} & \multirow{2}{*}{0.0099} & Main pipe & 1.168 & 51 & 3.15 \\
\hline & & & & Sub-pipe & 1.261 & 75 & 3.68 \\
\hline \multirow[b]{2}{*}{3} & \multirow[b]{2}{*}{0.015} & \multirow[b]{2}{*}{0.01} & \multirow{2}{*}{0.01212} & Main pipe & 1.431 & 51 & 4.73 \\
\hline & & & & Sub-pipe & 1.538 & 75 & 5.51 \\
\hline \multirow{2}{*}{4} & \multirow{2}{*}{0.005} & \multirow{2}{*}{0.013} & \multirow{2}{*}{0.005384} & Main pipe & 0.665 & 51 & 1.58 \\
\hline & & & & Sub-pipe & 0.745 & 75 & 1.84 \\
\hline \multirow{2}{*}{5} & \multirow{2}{*}{0.01} & \multirow{2}{*}{0.013} & \multirow{2}{*}{0.007615} & Main pipe & 0.953 & 51 & 3.15 \\
\hline & & & & Sub-pipe & 1.058 & 75 & 3.68 \\
\hline \multirow{2}{*}{6} & \multirow{2}{*}{0.01} & \multirow{2}{*}{0.01} & \multirow{2}{*}{0.00475} & Main pipe & 0.906 & 35.7 & 2.25 \\
\hline & & & & Sub-pipe & 1.049 & 50 & 2.74 \\
\hline
\end{tabular}

Table 3 shows changes in the average velocity, water level, and average shear stress, which are dependent variables, as modeling results when the slope, Manning's coefficient, and discharge were set as independent variables and varied in each case. In each case, the same slope, Manning's coefficient, and discharge were applied to both the main pipe and sub-pipe, and the average velocity, water level, and average shear stress were calculated. In cases 1 to 5 , the independent variables varied, but the water level, which is a dependent variable, was kept constant. The water level was intentionally matched to evaluate the performance of the complex cross-section at the maximum water level. In case 6 , the water level of the complex cross-section was $2 / 3$ of the maximum water level.

In all cases, the flow velocity and water level were higher in the sub-pipe than in the main pipe. Under the constant water level, the flow velocity increase rate of the sub-pipe compared to that of the main pipe was approximately $7 \%$ when the roughness coefficient was 0.01 (cases 1 to 3 ) and 11 to $12 \%$ when it was 0.013 (cases 4 and 5). As the roughness coefficient increased, the flow velocity increase rate in the sub-pipe compared to the main pipe became higher. When the slope and roughness coefficient were identical (cases 2 and 6), case 6 where the discharge and water level were low, exhibited a higher flow velocity increase rate in the sub-pipe compared to the main pipe (15\%).

The average shear stress is $\tau=\gamma R S\left(\mathrm{~N} / \mathrm{m}^{2}\right)$. If the specific weight of water is constant at $9800 \mathrm{~N} / \mathrm{m}^{3}$, the average shear stress is directly proportional to the hydraulic radius and slope. Under the same slope, the average shear stress is directly proportional to the hydraulic radius, which is determined by the water depth. Eventually, the average shear stress is determined by the water depth. In cases 1 to 5 , the average shear stress increase rate of the sub-pipe compared to that of the main pipe was constant at $16.5 \%$. This is because the water levels of the main pipe and sub-pipe were fixed at 51 and $75 \mathrm{~mm}$, respectively. In case 6, however, the average shear stress increase rate of the sub-pipe compared to that of the main pipe was $21.9 \%$. Unlike cases 1 to 5 , the water levels of the main pipe and sub-pipe ( 35.7 and $50 \mathrm{~mm}$ ) were relatively low in case 6 . While the absolute values of the flow velocity decreased, the relative flow velocity increase rate increased.

Table 4 shows the transport capabilities of the main pipe and sub-pipe in dry weather conditions measured in the pilot test. At a discharge of approximately $0.4 \mathrm{~L} / \mathrm{s}$, the flow of water in the two water channels is transitional flow. Manning's equation is suitable for completely rough flow, but it does not apply well in the flow in this experiment because the Reynolds number is low [15]. The discharge in the main pipe was measured to be $2 \%$ larger, but it was negligible. All parameters, such as the average velocity, hydraulic radius, Reynolds number, and average shear stress, were measured to be lower than in the sub-pipe. When hydraulic properties were compared according to the cross-sectional 
geometry change, it was found that the sub-pipe (complex cross-section) is more favorable than the main pipe.

Table 4. Pilot test results of flow performance for the main pipe and sub-pipe, discharge $Q(\mathrm{~L} / \mathrm{s})$, averaged velocity $U_{a v}(\mathrm{~m} / \mathrm{s})$, hydraulic radius $R_{h}(\mathrm{~m})$, Reynolds number $R e$, and average shear stress $\tau\left(\mathrm{N} / \mathrm{m}^{2}\right)$.

\begin{tabular}{cccccc}
\hline Test Case & $\boldsymbol{Q}(\mathrm{L} / \mathrm{s})$ & $\boldsymbol{U}_{\boldsymbol{a v}}(\mathrm{m} / \mathbf{s})$ & $\boldsymbol{R}_{\boldsymbol{h}}(\mathbf{m})$ & $\boldsymbol{R} \boldsymbol{\tau}$ & $\boldsymbol{\tau}=\gamma \boldsymbol{R S}\left(\mathrm{N} / \mathrm{m}^{2}\right)$ \\
\hline Main pipe & 0.423 & 0.371 & 0.0089 & 3285 & 0.65 \\
Sub-pipe & 0.412 & 0.436 & 0.0113 & 4902 & 0.829 \\
\hline
\end{tabular}

Because the shear stress in the sub-pipe was measured to be higher according to Table 4, this was verified through the sediment transport test. The pilot test equipment has a structure shown in Figure 3. The prepared sand was thrown to the top of the water channels. At the top, the sand rapidly flowed down under the influence of free fall of water, but it was accumulated and moved sequentially as the flow was stabilized soon. Small sand particles drifted, while large sand particles rolled over on the bottom. The former down at a high speed due to the surface flow velocity, but latter were easy to observe as their speed was slow. The average velocity of the sub-pipe was higher, and the apparent movement speed of the sand was higher.

Among the sand particles collected at the end of the water channels, only the largest sand particles were arranged, as shown in Figure 10. According to Hwang et al. [20], the sizes of the sand particles were analyzed using digital images. The lengths and widths of the largest particles collected from each channel were 2.49 and $2.2 \mathrm{~mm}$ in Figure 10a and 3.07 and $2.91 \mathrm{~mm}$ in Figure 10b, respectively. According to Equation (3), as large particles are transported, the corresponding flow has larger shear force. Because the sand particles transported in the sub-pipe are larger, it is judged that the tractive force of the complex cross-section is larger.

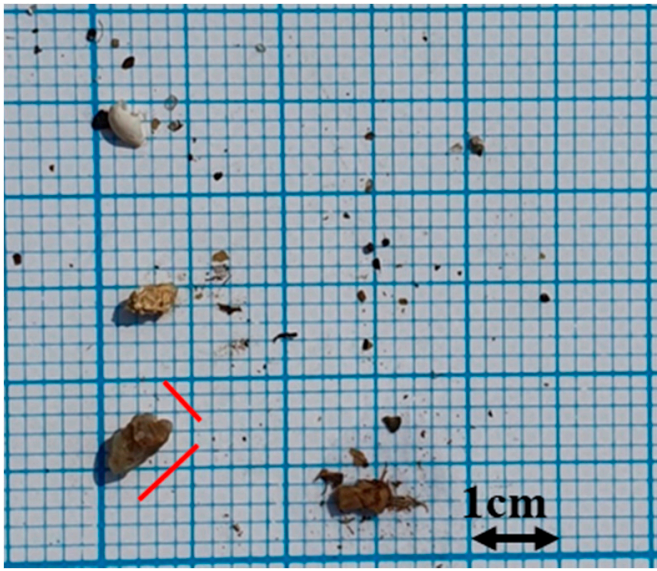

(a)

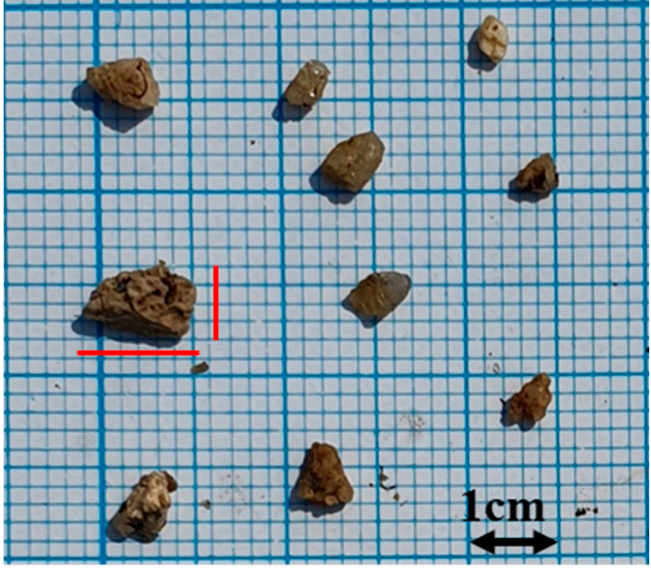

(b)

Figure 10. The largest sand grains having been transported from main pipe (a) and sub-pipe (b).

\subsection{Structural Strength Analysis}

The design of the complex cross-section followed Table 2 and Figure 8, and the concrete pipe that uses this cross-sectional geometry was designed as shown in Figure 11. The complex cross-section concrete pipe has a total length of $2.5 \mathrm{~m}$ with a main pipe diameter of $600 \mathrm{~mm}$ and a sub-pipe diameter of $200 \mathrm{~mm}$. It has a total height of $980.7 \mathrm{~mm}$, a pipe wall thickness of $75 \mathrm{~mm}$, and a bottom width of $320 \mathrm{~mm}$. The bottom of the pipe is flat, so it could stand directly on the foundation, and two grooves with a width of $200 \mathrm{~mm}$ and a depth of $80 \mathrm{~mm}$ were created for fastening transport belts. The maximum thickness 
between the bottom and invert is $154 \mathrm{~mm}$, and it is $74 \mathrm{~mm}$ at positions with the grooves. Both ends of the pipe have male and female sockets.

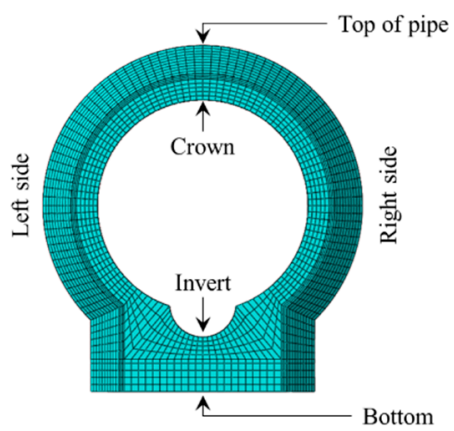

(a)

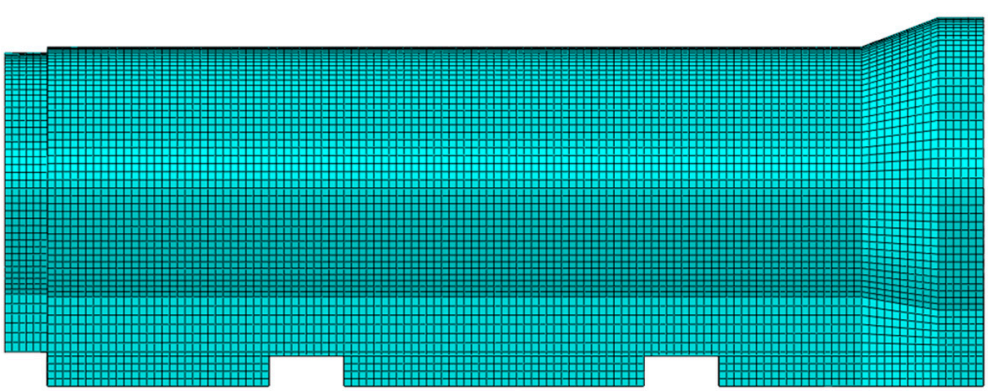

(b)

Figure 11. Design of the complex cross-section concrete pipe by 3D CFD mesh generation, (a) front view, (b) left side view.

Next, the strength of the actual complex cross-section reinforced concrete pipe was tested by preparing samples. A mold was constructed to make the design shape of Figure 11, and the complex cross-section reinforced concrete pipe was fabricated using the wet casting method. The three-edge bearing test generally suggested for concrete pipes was conducted. Test production was performed several times, and two samples were subjected to the breaking test. In this test, wood, a rubber plate, the concrete pipe, a rubber plate, and wood were piled from the bottom, and a load was applied on top of the pile using a Zig Jig (Figure 12).

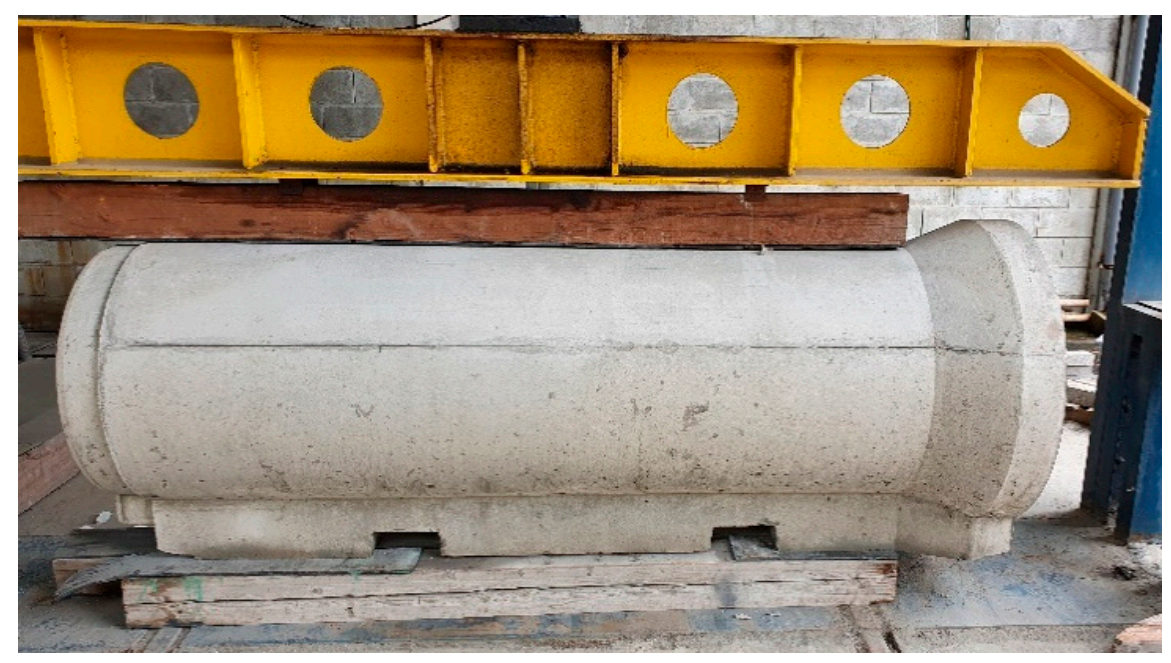

Figure 12. Three edge bearing test for complex cross-section reinforced concrete pipe.

The test results are shown in Table 5. KS F 4402 on VR pipes specifies the minimum strength criteria of $34.5 \mathrm{kN} / \mathrm{m}$ for crack load and $52 \mathrm{kN} / \mathrm{m}$ for failure load for a D600 mm pipe. The measured strengths exceeded these criteria. The difference from the existing circular pipe is that the crack load is high and there is no significant difference in failure load. According to the KS regulations, the failure load is 1.5 times higher than the crack load. For a complex cross-section reinforced concrete pipe, however, the failure load is approximately 1.1 times higher than the crack load. This failure behavior is caused by the sub-pipe. It appears that the rectangular concrete surrounding the sub-pipe acted as bedding and delayed the occurrence of cracks. 
Table 5. Results of a three-edge bearing test for a complex cross-section reinforced concrete pipe.

\begin{tabular}{ccc}
\hline Test Content & Test-1 & Test-2 \\
\hline Crack load & $50 \mathrm{kN} / \mathrm{m}$ & $57.8 \mathrm{kN} / \mathrm{m}$ \\
Failure load & $54 \mathrm{kN} / \mathrm{m}$ & $67.1 \mathrm{kN} / \mathrm{m}$ \\
\hline
\end{tabular}

Figure 13 shows the cracks that occurred after the breaking test. The cracks occurred in the crown, right side ( 3 o'clock), and left side ( 8 o'clock) directions. According to Watkins and Anderson [21], cracks in a circular pipe occur in four directions (crown, invert, left side, and right side) and in a symmetrical manner. The theory does not apply to actual concrete pipes because steel reinforcement and concrete are not uniform. A similar pattern, however, was observed. In a study by Scheperboer et al. [22], when a circular pipe failed, symmetrical cracks occurred in four directions. For an egg-shaped concrete pipe, which has a similar function to the pipe proposed in this study, symmetrical cracks also occurred in four directions. This indicates that the cracks in the 3 and 8 o'clock directions that occurred in the experiment of this study are symmetrical cracks, and vulnerable points on the left and right sides revealed themselves in the form of cracks.

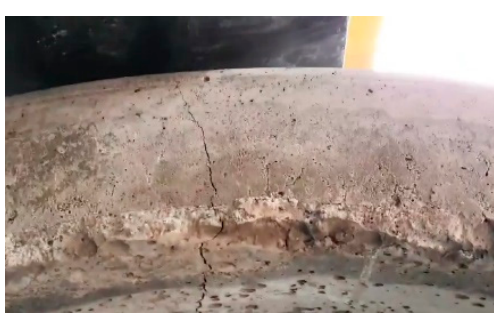

(a)

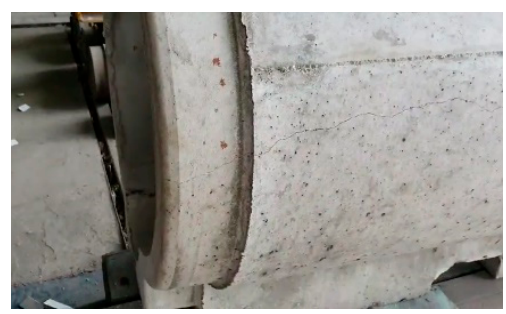

(b)

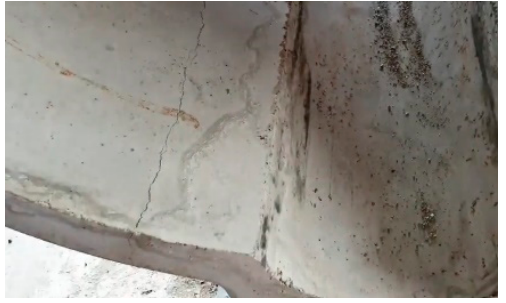

(c)

Figure 13. Crack position on a complex cross-section reinforced concrete pipe, (a) crown, (b) right side (3 o'clock), (c) left side (8 o'clock).

The breaking test of the egg-shaped concrete pipe, a type of the complex cross-section, can be compared. While cracks occurred in the $6 \mathrm{o}^{\prime}$ clock direction (invert) in the egg-shaped concrete pipe [22,23], this was not the case for the complex cross-section reinforced concrete pipe. This appears to be because the bottom of the complex cross-section reinforced concrete pipe is thicker than that of the egg-shaped concrete pipe and it is reinforced in a rectangular shape.

Identifying structural characteristics through the breaking test alone is difficult. Thus, the change in internal stress was numerically analyzed using FEA. The basic condition was assumed to be an unreinforced concrete pipe as presented in the methodology. The line loads were set to $30 \mathrm{kN} / \mathrm{m}$ (Model 1), which is slightly higher than the minimum crack load, and $67 \mathrm{kN} / \mathrm{m}$ (Model 2), which induced a failure in the previous breaking test, and the results are summarized in Table 6. The line load of Model 1 corresponds to the crack load of VR pipes, but slight displacement occurred with no damage. The numerical modeling results indicate that the minimum strength condition will also be satisfied in the actual breaking test. Model 2 exhibited more than two times larger displacement than Model 1, resulting in tensile damage. 
Table 6. Results of finite element analysis for complex cross-section concrete pipe.

\begin{tabular}{ccc}
\hline Contents & Model 1 & Model 2 \\
\hline Line load (boundary & $30 \mathrm{kN} / \mathrm{m}$ & $67 \mathrm{kN} / \mathrm{m}$ \\
condition) & $2.21 \mathrm{MPa}$ & $4.54 \mathrm{MPa}$ \\
Maximum tensile stress & $3.28 \mathrm{MPa}$ & $8.13 \mathrm{MPa}$ \\
Maximum compressive stress & $0.081 \mathrm{~mm}$ & $0.19 \mathrm{~mm}$ \\
Maximum displacement & - & Tensile damage \\
Damage & &
\end{tabular}

Figure 14 shows the distribution of tensile stress in the cross-section. The point that exhibited the highest tensile stress is the crown in both models. In Model 1a, with a relatively small line load, however, a slight concentration of tensile stress on the left and right sides and the invert was also observed. In Model $2 \mathrm{~b}$ with a large line load, tensile stress was relatively evenly distributed. The tensile stress rather decreased at the invert and increased at the bottom. The reason that no crack occurred at the invert in the above three edge bearing tests can be explained using this model. In other words, the rectangular bottom was subjected to tensile stress instead of the invert.

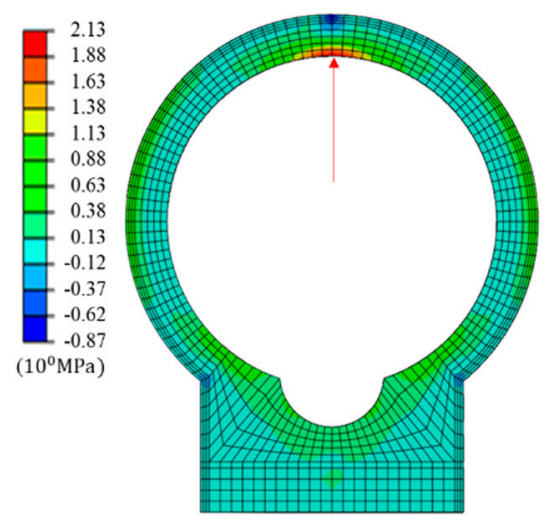

(a)

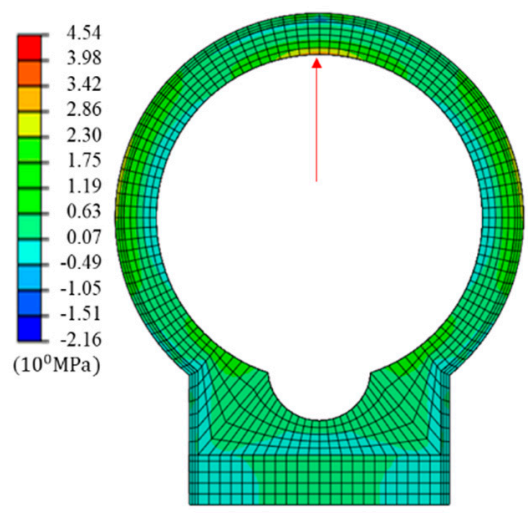

(b)

Figure 14. Tensile stress distribution of model 1 (a) and 2 (b).

Figure 15 shows the overall distribution of displacement in Model 2. Almost no displacement occurred at the bottom where the sub-pipe is located. The socket exhibited almost no displacement because no line load was applied to it. Slight displacement occurred on the left and right sides, but not at the level of causing damage. The crown subjected to the line load exhibited the largest displacement and damage.

In the three-edge bearing test and FEA, line loads were applied as an external force. These two line loads, however, were different. For FEA, a load was applied in a thin line without thickness. Since the concentration of force was large, deformation and damage intensively occurred in the crown. In the three-edge bearing test, however, rubber plates were used to prevent contact failure between the concrete pipe and the jig. Thus, the line load is the surface load, strictly speaking. The load was relatively evenly distributed and applied to the crown of the pipe.

Modeling was additionally performed to consider a case in which the load is evenly distributed on the pipe. Figure 16 shows a case in which only the self-weight of the pipe is considered. The distribution of tensile stress can be analyzed when the load is evenly distributed on the pipe. Although the maximum tensile stress was very low $(0.0549 \mathrm{MPa})$, the tensile stress was concentrated on the inner crown and the outside left and right sides as well as in the 5 and 7 o'clock directions. Due to the thick bottom, which was strong against tensile strength, the tensile strength was concentrated in the 5 and 7 o'clock directions next to it. According to Watkins and Anderson (2000) [21], cracking begins from the inside for the crown and invert and from the outside for the left and right sides, and Figure 16 shows 
the tensile stress distribution with a similar pattern. It implies that cracks may occur in the crown, on sides, and in the 5 and 7 o'clock directions, except for the invert, if load is distributed without concentration. These results are consistent with the crack locations in the three-edge bearing test.

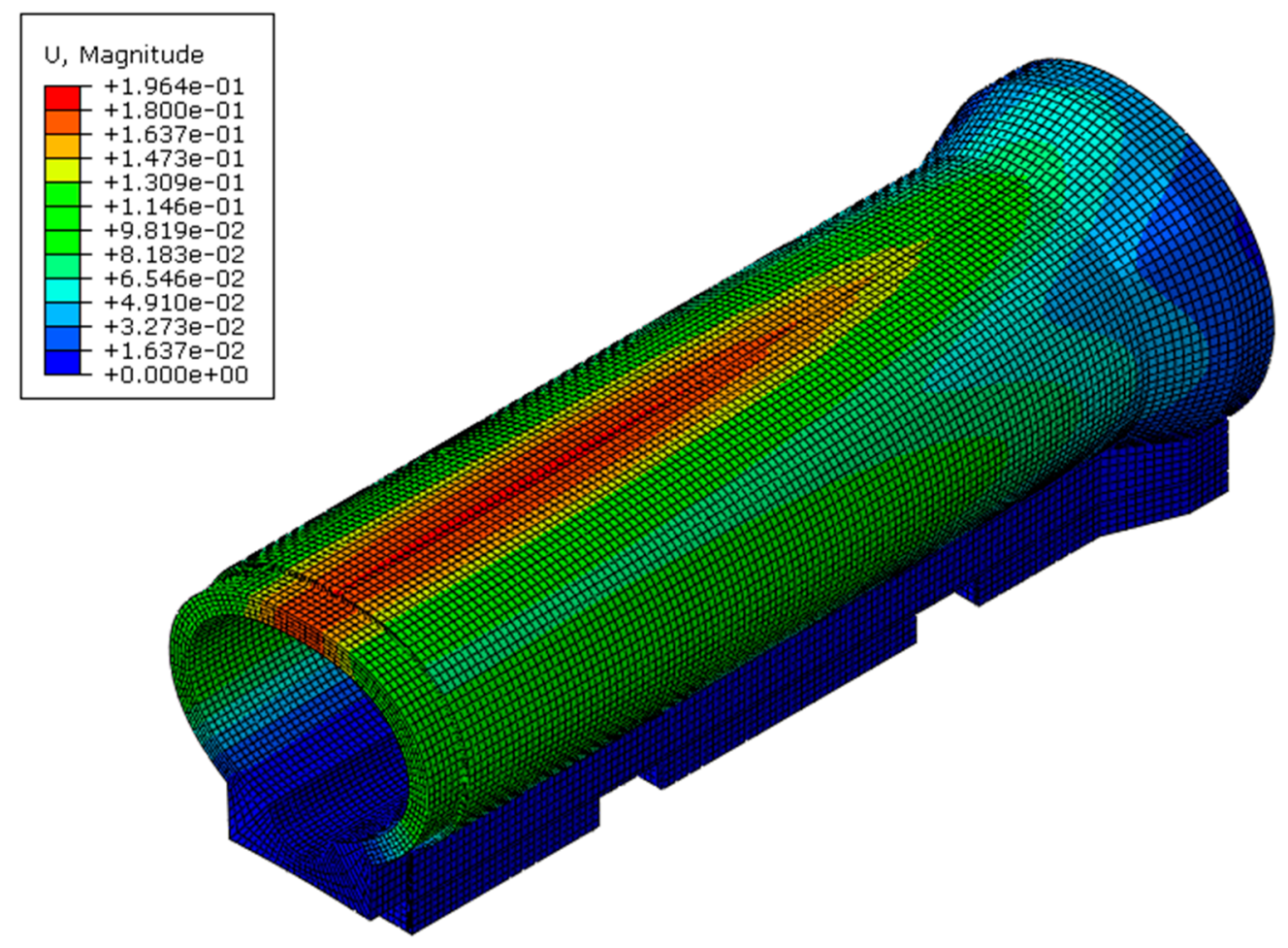

Figure 15. Displacement distribution by line load (Model 2 case).

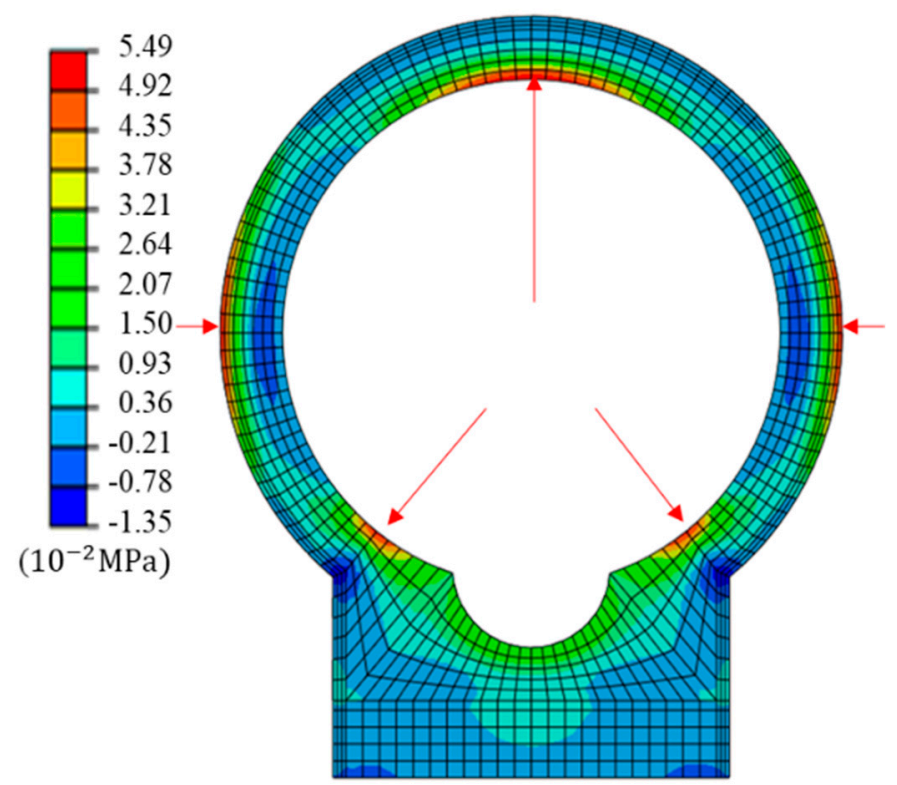

Figure 16. Tensile stress distribution by modeling under only concrete pipe weight.

\section{Discussion}

For complex cross-section reinforced concrete pipe, it is the most important to determine the size of the sub-pipe. This is because the flow velocity slightly decreases due to a reduction in hydraulic radius when the water level rises above the sub-pipe. Therefore, in 
this study, a size that can accommodate $99.85 \%$ of the sewage volume in the area where the pipe is expected to be used was determined using statistical analyses. Despite this design process, however, there will be cases in which the water level exceeds the sub-pipe depending on the region and situation. In such situations, however, there will be no influence on the flow velocity and sedimentation. The determination of the sub-pipe size is a matter of efficiency that is evaluated by the flow velocity increase rate compared to the sub-pipe size. The absolute flow velocity will be sufficiently high despite the low efficiency. The maximum flow velocity is developed in the middle (above invert) of the sewer pipe where the sub-pipe is located [24], and the flow velocity is faster compared to a case in which the water level is lower due to insufficient water. This can also be confirmed by the hydraulic characteristic curve in Figure 17. The flow velocity of partly filled complex cross-section pipe is theoretically calculated by single channel method or divided channel method $[25,26]$; sufficiently high velocity is generated when water level is above sub-pipe.

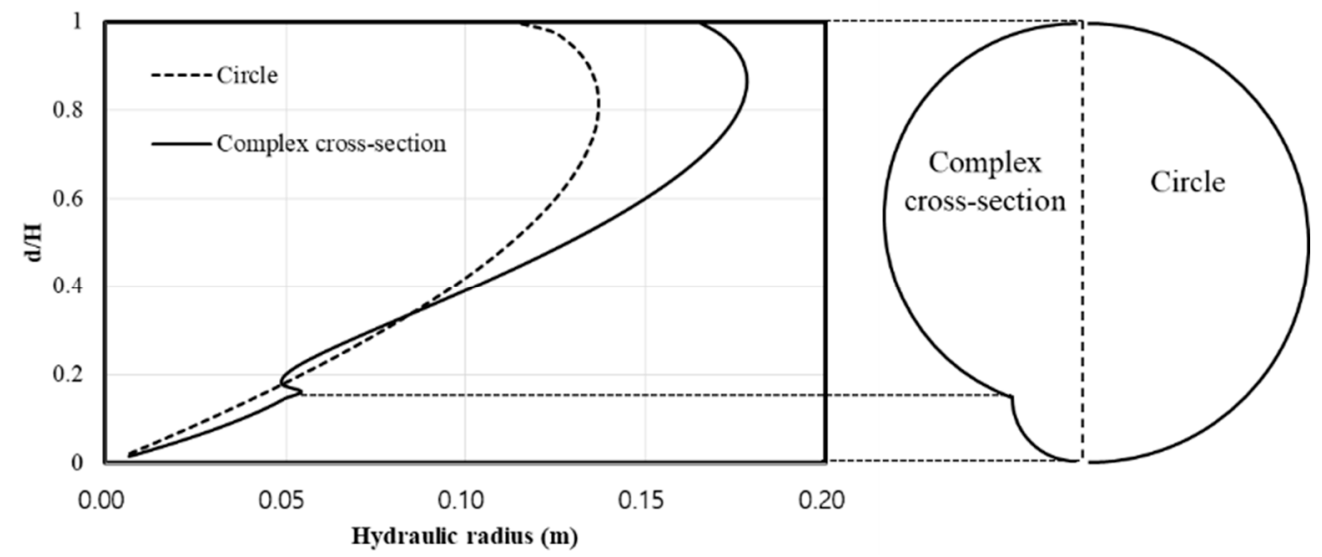

Figure 17. Hydraulic characteristic curve of circle and complex cross-section pipe.

The hydraulic benefits of the complex cross-section in the combined sewer system have been continuously asserted [8,27] since the mid-1800s [12] and mathematically verified. The complex cross-section, however, is complicated in terms of design. In Manning's equation, the hydraulic radius is a function of the cross-sectional area of flow and the wetted perimeter. For circular or square pipes, the equations to obtain the cross-sectional area of flow and the wetted perimeter are simple, and they do not change depending on the water level. For complex cross sections, however, when the water level rises and enters a different cross-section, the formula to obtain the hydraulic radius changes accordingly. In particular, if elliptical curves, such as egg-shaped, horseshoe, and semielliptical curves, or other similar curves are included, the complexity of the formula increases [28]. For the developed complex cross-section, however, the formula does not change depending on the water level because two circles overlap. In addition, it is easy to analyze because only the change in size is involved.

The proposed complex cross-section has hydraulic benefits compared to a circular pipe, but it has drawbacks in supply and construction. At present, the proposed complex cross-section reinforced concrete pipe cannot be mass-produced. While circular or square pipes are easy to install because they have no direction, the combined cross-section is difficult because it has top and bottom sections.

Circles that effectively disperse external force have the highest structural stability. Therefore, they are commonly used in daily life. For problems of sedimentation and odor that occur in sewer systems, however, simply dealing with the structural problem must be avoided. Hydraulic efficiency must also be sought. Based on egg-shaped pipes or the complex cross-section sewer pipes commonly constructed in the 18th century, it is judged that there is no problem in securing structural stability considering the shape of the pipe. However, there is a complex problem of the required strength compared to quality and quantity of materials. Computation structural analysis can partially solve the problem, 
but considerable experience and research on actual strength tests are required. Although some industries have investigated this problem, the experiment of this study provides a significant public record for the actual strength test and design of a new pipe.

Non-circular pipes (egg-shaped pipes) based on filament winding or centrifugal spraying technology using freely moldable polymer composites and reinforcing fibers [29] have been fabricated, but this study proposed a reinforced concrete pipe.

In South Korea, concrete pipes account for $43.8 \%$ and plastic pipes 38.9\% [30]. In general, rigid pipes made of concrete or clay are structurally safe and highly resistant to wear but vulnerable to cracking, whereas flexible pipes made of plastic materials are chemically safe, light, and easy to install but vulnerable to deformation [31,32]. It is usually difficult to determine the suitability of a material excluding special areas. The structural stability of concrete pipes has been preferred, and concrete pipes, more specifically Hume pipes, have been entirely used in combined sewer systems. Furthermore, a common practice for the replacement of old or deteriorated pipes is to construct pipes of same material as in existing pipes. Therefore, producing complex cross-section pipes with concrete is the practical method of maximizing usability. It is necessary to continue research on complex cross-section concrete pipes.

\section{Conclusions}

In the combined sewer system, sedimentation and odor occur in dry weather conditions due to a small sewage flow rate. To address this problem, a complex cross-section reinforced concrete pipe was proposed in this study. In addition, the design of the crosssection, production of a prototype, and analysis of structural strength were conducted for developing the proposed pipe. The complex cross-section had the form of two connecting circles of different sizes, and the final complex cross-section was determined considering the efficiency for increasing the flow velocity and the applicability to actual sites. The determined complex cross-section showed the effect of increasing the flow velocity by 11 to $12 \%$ compared to a circular pipe, and the flow velocity increase rate increased by more than $15 \%$ depending on the water level. Because these values were based on when the sub-pipe of the complex cross-section was full, the increase rate may vary if the water level changes. In the tractive force test, the complex cross-section also exhibited excellent performance. The complex cross-section reinforced concrete pipe was then designed in the form of attaching bedding to the bottom. When the pipes of D600/D200 were fabricated and subjected to the breaking test, there was no strength reduction as the results exceeded the existing crack and failure criteria for reinforced concrete circular pipes. The bedding caused by the sub-pipe at the bottom delayed cracking, and cracks occurred only in the crown and on the left and right sides, except for the invert, unlike the circular pipe. The proposed complex cross-section reinforced concrete pipe can be immediately applied to the field based on its hydraulic and structural performance, but continued research on methods for mass production and construction is required.

Author Contributions: Conceptualization and writing-original draft preparation, H.W.J.; investigation and data curation, J.-H.K.; writing-review and editing, D.D.K.; visualization and supervision, S.S.Y. All authors have read and agreed to the published version of the manuscript.

Funding: This research received no external funding.

Institutional Review Board Statement: Not applicable.

Informed Consent Statement: Not applicable.

Data Availability Statement: Not applicable.

Acknowledgments: This work was supported by the Korea Institute of Civil Engineering and Building Technology (2021-0108).

Conflicts of Interest: The authors declare no conflict of interest. 


\section{References}

1. San Francisco. City and County of San Francisco 2030 Sewer System Master Plan. 2009. Available online: https://www. gsweventcenter.com/Draft_SEIR_References/2010_12_SFPUC_TM509.pdf (accessed on 26 October 2021).

2. WESD and WCSD (Wastewater Engineering Services Division \& Wastewater Collection Systems Division). Collection System Odor Control Master Plan 2017. 2017. Available online: https://www.lacitysan.org/cs/groups/sg_cw/documents/document/ y250/mdiw/ \{\}edisp/cnt020340.pdf (accessed on 26 October 2021).

3. Ji, H.W.; Yoo, S.S. The measures to reduce sewer odor in South Korea through sewer odor reduction system in Los Angeles and San Francisco. J. Korean Soc. Water Wastewater 2018, 32, 445-451. [CrossRef]

4. Husain, I.A.; Alkhatib, M.A.F.; Jammi, M.S.; Mirghani, M.E.S.; Zainudin, Z.B.; Hoda, A. Problems, control, and treatment of fat, oil, and grease (FOG): A review. J. Oleo Sci. 2014, 63, 747-752. [CrossRef] [PubMed]

5. Stein, S.M.; Dou, X.; Umbrell, E.R.; Jones, J.S. Storm sewer junction hydraulics and sediment transport. In Proceedings of the WRPMD'99: Preparing for the 21st Century, Tempe, AZ, USA, 6-9 June 1999; pp. 1-11.

6. Crispino, G.; Pfister, M.; Gisonni, C. Supercritical flow in junction manholes under invert- and obvert-aligned set-ups. J. Hydraul. Res. 2019, 57, 534-546. [CrossRef]

7. Cho, J.; Song, H. A study of controls and complaints by odor in domestic sewer system. In Proceedings of the 2011 Joint Autumn Conference, Water Wastewater \& Korea Society Water Environment, Deajeon, Korea, 2-3 November 2011; pp. $692-693$.

8. Bizier, P. Gravity Sanitary Sewer Design and Construction; American Society of Civil Engineers and Water Environment Federation: Reston, VA, USA, 2007; pp. 139-141.

9. Beichert, J. Influence of sewer sediments on the overflow load for various combined sewer systems. Water Sci. Technol. 1992, 25, 217-224. [CrossRef]

10. Ahyerre, M.; Chebbo, G. Identification of in-sewer sources of organic solids contributing to combined sewer overflows. Environ. Technol. 2002, 23, 1063-1073. [CrossRef] [PubMed]

11. Korea Construction Standards Center. Korea Construction Standards; Construction Standards for Sanitary Sewer Pipeline. Available online: https:/ / www.kcsc.re.kr/StandardCode/Viewer/3359\#title-43 (accessed on 10 November 2021).

12. Schladweiler, J.M.; The History of Sanitary Sewer: Pipes-Brick. AZ Water Association, NASSCO, Collection Systems Committee of the Water Environment Federation. 2020. Available online: http://www.sewerhistory.org/photosgraphics/pipes-brick/ (accessed on 29 September 2021).

13. ACPA (American Concrete Pipe Association). Concrete Pipe Design Manual; ACPA: Irving, TX, USA, 2011; pp. 83-86. Available online: https:/ / www.concretepipe.org/wp-content/uploads/2014/09/cp-manual.pdf (accessed on 11 November 2021).

14. Regueiro-Picallo, M.; Naves, J.; Anta, J.; Puertas, J.; Suárez, J. Experimental and numerical analysis of egg-shaped sewer pipes flow performance. Water 2016, 8, 587. [CrossRef]

15. Douglas, J.F.; Gasiorek, J.M.; Swaffield, J.A. Fluid Mechanics, 3rd ed.; Longman: Harlow, UK, 1995; pp. $460-474$.

16. George, E.P.; Hunter, J.S.; Hunter, W.G. Statistics for Experimenters: Design, Innovation, and Discovery; Wiley: New York, NY, USA, 2005; pp. 27-33.

17. ANSYS CFX. ANSYS CFX-Solver Theory Guide; ANSYS CFX Release: Canonsburg, PA, USA, 2012; pp. 69-118.

18. Korean Industrial Standards. 2021. KS F 4402: Vibrated and Rolled Reinforced Concrete Pipe. Available online: https: / / standard.go.kr/KSCI/standardIntro/getStandardSearchView.do?pageIndex=1\&pageUnit=10\&ksNo=KSF4402\& tmprKsNo=KSF4402\&reformNo=19\&menuId=919\&topMenuId=502\&upperMenuId=503 (accessed on 11 November 2021).

19. Hafezolghorani, M.; Hejazi, F.; Vaghei, R.; Jaafar, M.S.B.; Karimzade, K. Simplified damage plasticity model for concrete. Struct. Eng. Int. 2017, 27, 68-78. [CrossRef]

20. Hwang, T.-J.; Cho, J.-Y.; Lee, K.-H. Gradation curve of aggregate using digital image process. J. Korean Soc. Hazard Mitig. 2010, 10, 31-37.

21. Watkins, R.K.; Anderson, L.R. Structural Mechanics of Buried Pipes; CRC Press: New York, NY, USA, 2000; pp. 1-28.

22. Scheperboer, I.C.; Luimes, R.A.; Suiker, A.S.; Bosco, E.; Clemens, F.H.L.R. Experimental-numerical study on the structural failure of concrete sewer pipes. Tunn. Undergr. Space Technol. 2021, 116, 104075. [CrossRef]

23. Stanić, N.; Jeroen, L.; Theo, S.; François, C. Relating the structural strength of concrete sewer pipes and material properties retrieved from core samples. Struct. Infrastruct. Eng. 2017, 13, 637-651. [CrossRef]

24. Manica, R. Sediment gravity flows: Study based on experimental simulations. Hydrodyn. Nat. Water Bod. 2012, 1, $263-286$.

25. Crispino, G.; Gisonni, C.; Iervolino, M. Flood hazard assessment: Comparison of 1D and 2D hydraulic models. Int. J. River Basin Manag. 2015, 13, 153-166. [CrossRef]

26. Parsaie, A.; Najafian, S.; Yonesi, H. Flow discharge estimation in compound open channel using theoretical approaches. Sustain. Water Resour. Manag. 2016, 2, 359-367. [CrossRef]

27. Ji, H.W.; Yoo, S.S.; Koo, D.D.; Kang, J.H. Analysis of the flow performance of the complex cross-section module to reduce the sedimentation in a combined sewer pipe. Water 2020, 12, 3291. [CrossRef]

28. Swamee, P.K.; Bhargava, R.; Sharma, A.K. Noncircular sewer design. J. Environ. Eng. 1987, 113, 824-833. [CrossRef]

29. Czel, G.; Czigany, T. Analysing fluctuation of material properties of non-circular profile filament wound composite pipes along perimeter of cross-section. Plast. Rubber Comp. 2011, 40, 369-373. [CrossRef]

30. Ministry of Environment. 2019 Sanitary Sewer Statics. 2021. Available online: https://www.hasudoinfo.or.kr/stat/statRefDetail. do (accessed on 29 September 2021). 
31. Singh, A.; Adachi, S. Bathtub curves and pipe prioritization based on failure rate. Built Environ. Proj. Asset Manag. 2013, 3, 105-122. [CrossRef]

32. Mohammadi, M.M.; Najafi, M.; Kermanshachi, S.; Kaushal, V.; Serajiantehrani, R. Factors Influencing the Condition of Sewer Pipes: State-of-the-Art Review. J. Pipe. Syst. Eng. Prac. 2020, 11, 03120002. [CrossRef] 